\title{
Cuidado cotidiano da criança: necessidades e vulnerabilidades na perspectiva de
} mães adolescentes

\author{
Jaqueline Silva Santos ${ }^{1}$, Marina Sayuri Yakuwa ${ }^{2}$, Raquel Dully Andrade ${ }^{3}$, \\ Nayara Cristina Pereira Henrique ${ }^{4}$, Débora Falleiros de Mello ${ }^{5}$
}

\author{
${ }^{1}$ Enfermeira, Mestre em Enfermagem em \\ Saúde Pública. Discente do Programa de Pós- \\ Graduação Enfermagem em Saúde Pública, \\ nível Doutorado, da Escola de Enfermagem de \\ Ribeirão Preto da Universidade de São Paulo. \\ Ribeirão Preto, SP, Brasil. E-mail: \\ jaquelinessantos@usp.br. \\ ${ }^{2}$ Enfermeira, Mestre em Enfermagem em \\ Saúde Pública. Discente do Programa de Pós- \\ Graduação Enfermagem em Saúde Pública, \\ nível Doutorado, da Escola de Enfermagem de \\ Ribeirão Preto da Universidade de São Paulo. \\ Ribeirão Preto, SP, Brasil. E-mail: \\ myakuwa@usp.br. \\ ${ }^{3}$ Enfermeira, Doutora em Enfermagem em \\ Saúde Pública. Professor Substituto da \\ Universidade do Estado de Minas Gerais. Belo \\ Horizonte, MG, Brasil. E-mail: \\ radully@gmail.com. \\ ${ }^{4}$ Enfermeira. Discente do Programa de Pós- \\ Graduação Enfermagem em Saúde Pública, \\ nível Mestrado, da Escola de Enfermagem de \\ Ribeirão Preto da Universidade de São Paulo. \\ Ribeirão Preto, SP, Brasil. E-mail: \\ nayara.henrique@usp.br. \\ ${ }^{5}$ Enfermeira, Doutora em Enfermagem. \\ Professora Associado da Escola de \\ Enfermagem de Ribeirão Preto da \\ Universidade de São Paulo. Ribeirão Preto, SP, \\ Brasil. E-mail: defmello@eerp.usp.br.
}

Recebido: 03/10/2015

Aceito: 25/07/2016.

Publicado: 22/12/2016.

Como citar esse artigo:

Santos JS, Yakuwa MS, Andrade RD, Henrique NCP, Mello DF. Cuidado cotidiano da criança: necessidades e vulnerabilidades na perspectiva de mães adolescentes. Rev. Eletr. Enf. [Internet]. 2016 [acesso em: ____18:e1199. Disponível em: http://dx.doi.org/10.5216/ree.v18.37684.

\section{RESUMO}

Este estudo objetivou analisar os cuidados às crianças na perspectiva de mães adolescentes, em busca da identificação de vulnerabilidades e necessidades no âmbito do cuidado de enfermagem. Trata-se de pesquisa exploratória com análise qualitativa temática indutiva dos dados, a partir de entrevistas gravadas com 20 mães adolescentes de crianças entre seis meses e menores de dois anos de idade, cadastradas e acompanhadas por equipes de Saúde da Família do município de Passos, Minas Gerais, Brasil. Os relatos maternos expressam aspectos sobre o cuidado cotidiano da criança, a atenção às suas necessidades, o enfrentamento de dificuldades e o reconhecimento de situações vulneráveis. O cuidado materno na adolescência apresentou-se como uma experiência singular, com relatos maternos que apontam aspectos a serem mais explorados pelos profissionais de saúde, em especial pela enfermagem, em busca de oferta de apoio e incremento da confiança materna.

Descritores: Gravidez na Adolescência; Cuidado da Criança; Cuidados de Enfermagem; Saúde da Criança; Enfermagem de Atenção Primária.

\section{INTRODUÇÃO}

Os cuidados cotidianos às crianças são essenciais para atender necessidades e garantir direitos, levando em conta sua condição de vulnerabilidade $^{(1-2)}$. As crianças têm necessidades essenciais, que envolvem relacionamentos sustentadores contínuos, proteção física, segurança, experiências que respeitem as diferenças individuais, 
situações adequadas ao desenvolvimento, estabelecimento de limites e de expectativas, comunidades estáveis, amparadoras e com continuidade cultural $^{(3)}$. A concepção de vulnerabilidade remete à fragilidade e dependência da criança, não se restringindo às questões de inserção social, mas também aos relacionamentos entre crianças e adultos ${ }^{(4)}$.

A adolescência é uma fase de profundas mudanças ${ }^{(5)}$, em que o sujeito adolescente deve ser vislumbrado de acordo com suas singularidades e interações com o contexto familiar e social ${ }^{(6)}$. A maternidade na adolescência apresenta-se como uma situação peculiar que, dependendo da conjuntura e das perspectivas de vida da adolescente, pode assumir diferentes significados e contornos ${ }^{(5)}$. Em um contexto com oportunidades sociais limitadas, a gravidez-maternidade emerge como uma forma de maior autonomia, comprovação da feminilidade e reconhecimento social, além de possibilitar a vivência de certos afetos, como amor e carinho(7).

Ao assumir as responsabilidades sobre o cuidado da criança, a mãe adolescente pode referir despreparo e insegurança, enfrentando dificuldades para identificar as necessidades do filho e lidar com situações cotidianas, por exemplo, manejo de cólicas e choros noturnos ${ }^{(8-9)}$. Destarte, a adolescente necessita de uma rede de apoio fortalecida ${ }^{(10)}$, que pode ser composta por familiares, companheiro, amigos, profissionais da saúde, assistentes sociais e professores ${ }^{(11)}$.

$A$ atenção à mãe adolescente representa um desafio para os profissionais da saúde ${ }^{(10)}$, revelando a importância da capacitação do profissional para identificar e lidar com as demandas da adolescente e da criança, compreendendo a conjuntura social e cultural na qual a maternidade se desenvolve ${ }^{(12)}$ e evitando ações prescritivas e impositivas no relacionamento com a adolescente ${ }^{(8)}$.

Nesse cenário, problematizar questões referentes ao cuidado infantil, diante das particularidades da maternidade na adolescência, torna-se relevante para a identificação de necessidades e vulnerabilidades ao desenvolvimento na infância, presentes no cuidado cotidiano, e o fortalecimento das potencialidades da adolescente mãe ${ }^{(13-14)}$. Assim, o objetivo do presente estudo foi analisar os cuidados às crianças na perspectiva de mães adolescentes, em busca da identificação de vulnerabilidades e necessidades no âmbito do cuidado de enfermagem.

\section{MÉTODOS}

Trata-se de uma pesquisa exploratória com abordagem qualitativa ${ }^{(15)}$ realizada na cidade de Passos, Minas Gerais, no ano de 2014.

Participaram mães adolescentes que atendiam aos seguintes critérios de inclusão: idade entre 12 e 18 anos, filho com idade entre seis meses e menor de dois anos, cadastrado e acompanhado pela equipe de Saúde da Família (SF). Os critérios de exclusão foram: mães que se encontravam em tratamento devido a problemas de saúde mental, interrupção do seguimento nas Unidades de Saúde da Família (USF), mudança da área de abrangência das USF, ou não ser encontrada após três tentativas no domicílio em horários diferentes. 
As 17 equipes de SF do município foram dispostas em uma sequência, em ordem decrescente, de acordo com a quantidade de mães adolescentes registrada no período de 2012 e 2013. Primeiramente, foram abordadas as adolescentes pertencentes à área de abrangência da primeira USF da sequência elaborada, e assim sucessivamente, até que ocorresse a saturação teórica ${ }^{(16)}$.

Para a coleta de dados, utilizou-se a entrevista semiestruturada, gravada, com questões norteadoras, que buscaram levantar aspectos sobre dificuldades e facilidades percebidas pelas adolescentes no cuidado cotidiano com a criança. A entrevista foi realizada pela primeira autora no domicílio de cada mãe adolescente, após consentimento de seu representante legal e assentimento da adolescente, com duração média de 50 minutos. 0 alcance do objeto de estudo por meio das entrevistas foi baseado em saturação teórica ${ }^{(16)}$, que ocorreu com a 20 å entrevista. Deve-se pontuar que não houve recusa à participação neste estudo. As participantes foram denominadas de E1, E2...E20.

Para a análise dos dados foi utilizada a análise temática indutiva, processo de codificação embasado nos próprios dados coletados ${ }^{(15)}$. Nesse caminho, emergiram duas unidades temáticas que traduzem os principais cuidados relatados pelas entrevistadas: $O$ cuidado da criança e a atenção às suas necessidades; $O$ cuidado da criança e o reconhecimento de vulnerabilidades.

As entrevistas somente foram realizadas após aprovação do projeto de pesquisa pelo Comitê de Ética da Fundação de Ensino Superior de Passos (FESP), Parecer no 507.936, CAAE: 21800413.9.0000.5112. Utilizou-se um Termo de Consentimento Livre e Esclarecido e um Termo de Assentimento, seguindo as diretrizes e normas regulamentadoras sobre pesquisa envolvendo seres humanos.

\section{RESULTADOS}

As participantes do estudo foram, predominantemente, adolescentes com a idade entre 16 e 17 anos, estudantes, solteiras, que possuíam renda familiar de até um salário mínimo, e tinham um filho. No que concerne ao cuidado cotidiano, 17 mães adolescentes relataram contar com a ajuda de outras pessoas, citando a avó materna e o pai da criança, assim como a sogra, o pai/padrasto, a avó, as irmãs, as primas e as tias da adolescente.

De modo geral, o material qualitativo mostrou percepções da mãe adolescente sobre algumas necessidades da criança que precisam ser satisfeitas, bem como dificuldades enfrentadas no cuidado cotidiano, que refletem vulnerabilidades à saúde infantil.

\section{O cuidado da criança e a atenção às suas necessidades}

Nos relatos das mães adolescentes, a criança é vista de acordo com algumas necessidades. Aqui, destaca-se a relevância da presença de um cuidador principal, da figura materna e paterna. A participação e o envolvimento dessas pessoas são apontados com relação ao estabelecimento de vínculos afetivos com a criança.

Eu dou muito carinho para ela [filha]. O pai dela trabalha o dia inteiro. Quando ele chega, ela [filha] fica 
alegrinha por causa dele. [...] Eu e o pai dela temos que dar muito amor e muito carinho para ela e temos que viver bem, com muito amor, porque a criança sente. (E10)

Eu acho que toda criança precisa da presença do pai. Precisa, mas, ele [filho] é muito agarrado comigo, estando junto comigo acho que ele [filho] fica feliz, eu dou muito carinho para ele [filho]. (E14)

A brincadeira aparece como uma forma de estabelecer interação com a criança. A família pode contribuir nesses momentos, o que implica tempo e disponibilidade para cuidar e interagir.

Eu acho que a família pode ajudar, assim, brincando com eles [crianças], deixando eles felizes. (E6)

Eu brinco bastante com ele [filho], mas a minha mãe [avó] brinca mais. Ela tem mais paciência. (E18)

O reconhecimento da importância de suportes institucionais para o cuidado cotidiano da criança foi mencionado. Há destaque para a creche como contribuição ao desenvolvimento dela.

A creche foi boa para ela também, porque ela é muito sozinha, ela brinca só com uma menininha que mora aqui perto [...] Agora, lá na creche, tem muita criança para ela brincar. Ela gosta, não chora para ir, ela gosta. (E12)

Alguns outros cuidados cotidianos, como alimentação, higiene corporal e acompanhamento mensal do crescimento e desenvolvimento infantil são elencados como importantes para o conforto e proteção da criança.

Cuidar bem da saúde dele é importante, alimentando ele bem, deixando ele sempre limpinho. (E5)

Todo mês eu levo ela para pesar. Esses dias atrás eu levei ela na pediatra para dar uma revisão geral nela, uma consulta de rotina, para ver como que ela estava, se ela estava bem. (E10)

A compreensão das necessidades infantis peculiares a cada etapa do desenvolvimento auxilia a mãe adolescente a adotar medidas para proteger a criança.

Ele está em uma fase que ele quer atenção, quer brincar, e tem vezes que o meu marido está assistindo televisão e ele acha que o nosso filho tem que ficar no colo dele quietinho [...] E o nosso filho não quer assistir aquilo, ele gosta de desenho, e tem um limite também, ele não fica muito tempo assistindo. [...] Aí, meu marido estressa por causa disso. [...] aí, eu vou lá e pego o nosso filho, para ele não continuar estressando, porque senão acho que ele pode até bater nele, de tanto que ele grita. (E5)

O cuidado da criança e o reconhecimento de vulnerabilidades

Durante o cuidado cotidiano da criança, as mães adolescentes referem enfrentar dificuldades. Aspectos ligados ao despreparo e insegurança no desempenho do cuidado infantil aparecem nos relatos, mostrando necessidade de informação e interação para ampliar as suas experiências.

Está sendo muito complicado cuidar dela, eu achei que era mais fácil. É minha primeira filha, então, está sendo muito complicado. [...]. Eu acho cuidar dela difícil, porque eu não tinha experiência. (E20) 
Tive mais dificuldade na hora de dar banho. [...]. Ele era muito pequenininho e eu ficava até com medo de machucar ele, tadinho. (E14)

[...] ela ficou a noite inteira acordada com dor no ouvidinho e eu não sabia o que era. Eu colocava a toalhinha no ouvidinho dela, tentava fazer ela dormir, mas, ela ficou a noite inteira acordada chorosa [...] Depois que eu fui ficar sabendo que talvez fosse o ouvidinho dela que estivesse doendo [...] (E10)

Diante desse quadro de insegurança e medo, a figura da avó da criança é vista como referência para o cuidado cotidiano, fornecendo apoio.

Quando eu estava grávida eu pensei que iria ser difícil cuidar dele, mas minha mãe me ajuda muito, e vi que não é tão difícil assim. [...] Nossa, eu morria de medo de dar banho nele. Aí, a minha mãe, no começo, ela começou a dar o banho nele, e foi me ensinando. Depois, eu aprendi, perdi o medo de dar banho nele. (E2) Minha mãe foi fazendo e me dando segurança. Ela ia falando: "É desse jeito, desse jeito". (E9)

As mães adolescentes também mencionaram dificuldades relacionadas à amamentação. As situações retratam dificuldades no manejo com a criança, para saciar a fome, controlar o choro e equilibrar o sono.

Eu tive dificuldades para amamentar. A minha filha desmamou com três meses, eu tinha pouco leite e ela desmamou [...] Com o meu filho aconteceu a mesma coisa [...] Eu não tive orientação de nenhum profissional, e também eu fui desanimando, sabe? O meu bebê chorava muito, e eu ficava nervosa com aquilo, ele estava com fome e o meu leite não sustentava porque produzia pouco leite, aí desanimei de amamentar e comecei a dar o outro leite [aleitamento artificial]. (E6)

A introdução da alimentação complementar, no tocante à aceitação da criança, aparece como momento de dificuldade no cuidado, na oferta de novos alimentos e no estabelecimento de limites.

Foi bem complicado na hora de dar papinha porque ela é bem enjoada para comer. Ela não gosta de papinha. [...] Se você põe a carne ela não come, se você põe uma verdura ela não come, é assim. [...]. Mas, agora, as verduras e os legumes eu faço ela comer, insisto até ela comer, o arroz que não tem jeito mesmo. Eu amasso bastante a batata, a abobrinha, aí ela come. Mas, se por arroz, aí ela joga tudo fora. (E20)

Outro aspecto de extrema importância é a ocorrência de tristeza após o parto. A ambivalência de sentimentos com relação à criança causa imenso sofrimento e angústia na mãe adolescente:

Eu fui no quarto, olhei nela assim, sabe quando você olha na criança e não sente vontade de pegar ela, não sente vontade de ter ela perto de você? Aconteceu desse jeito. Ela ficou chorando, chorando, chorou um tempão. E eu vim e sentei aqui no sofá. E fiquei sentada aqui e ela lá no quarto chorando. Quando eu fui lá no quarto ela já estava com a boca até roxa de tanto chorar. Aí eu pensei: 'Tenho que pegar ela, ela é minha filha'. Peguei ela, amamentei ela, mas, não querendo, sabe? Não querendo pegar, amamentar ela. Eu comecei a chorar, chorei muito. [...] Falar que eu acostumei com ela faz pouco tempo, aceitar, falar: 'Ela é minha filha'. [...] Mas, agora, para mim já está tudo bem. Hoje eu não consigo é ficar longe dela. (E17) 
A participação do pai também é relatada pelas mães adolescentes como um aspecto pertinente ao desenvolvimento da criança. Apontam dificuldades com a ausência ou pouca participação do pai tanto no cuidado cotidiano da criança quanto no auxílio financeiro.

O pai dele não trabalha, ele também é de menor. Mas, eu e a minha família cuidamos dele, não precisa de pensão do pai não. Acho, assim, se tivessem de dar a pensão, ajudar a gente, já deveriam ter começado, porque eles [a família do pai da criança] sabem que não é fácil cuidar de um filho, a mãe dele [avó paterna da criança] já deveria ter começado a ajudar, mas não. (E2)

A questão relacionada a ambientes saudáveis para a criança crescer e se desenvolver também é apontada. Ambientes inseguros, particularmente ligados à violência social, mostram-se como preocupantes. Semana passada eu e meu marido chegamos à conclusão que a gente precisa mudar daqui. Aqui é um lugar perigoso, um amigo nosso foi morto e a gente ficou muito abalado com isso. Eu temo pela minha filha. Crescer em um ambiente assim, sabe, acho que não ia fazer bem para ela, ela precisa viver em um local mais seguro, mais tranquilo. (E17)

\section{DISCUSSÃO}

Nos relatos maternos, foi possível apreender aspectos referentes ao cuidado, com ênfase para o reconhecimento de algumas necessidades da criança e de situações vulneráveis presentes no cotidiano. As mães adolescentes participantes do estudo têm uma visão ampliada das necessidades da criança, abordando questões relacionadas às necessidades físicas, emocionais e sociais.

Aspectos relacionados ao suprimento das necessidades de crescimento e desenvolvimento infantil podem ser apreendidos ao se considerar as perspectivas maternas no cuidado da saúde da criança ${ }^{(2)}$. No que se refere às necessidades infantis, deve-se pontuar que a presença e o envolvimento dos pais no cotidiano de cuidados, a vigilância constante para a proteção física e emocional, assim como as experiências que estimulam o desenvolvimento da criança, aparecem como elementos facilitadores da promoção da segurança infantil ${ }^{(2)}$.

A falta de apoio ou o pequeno apoio do pai da criança é uma realidade vivenciada por uma parcela significativa das adolescentes que se tornam mães ${ }^{(11,17)}$. No presente estudo ficou evidenciado que as adolescentes reconhecem a importância da figura paterna para a criança e desenham caminhos para compensar essa ausência, como redobrar a atenção e o carinho ofertado ao filho.

A creche é vista como um apoio para a mãe adolescente que pode voltar a trabalhar e/ou estudar. No que concerne ao desenvolvimento infantil, a creche emerge como uma instituição relevante no contexto da aprendizagem e da aquisição de habilidades para a convivência social, reconhecida como elemento de suporte às famílias no cuidado de crianças $^{(2,18)}$.

O universo que envolve o cuidado de um novo ser exige a incorporação de alterações na rotina dos pais, principalmente de sono e repouso, para suprir as necessidades e exigências dos bebês (mamadas sem 
horários definidos, choro, dores, troca de fraldas, entre outras) ${ }^{(8)}$. As narrativas das mães adolescentes assinalam dificuldades vivenciadas no cuidado cotidiano da criança, o que aponta a necessidade de acolhida materna ${ }^{(9)}$. Em função disso, o cuidado do filho é vislumbrado pelas adolescentes "como uma busca pela superação e afirmação da condição de mãe" ${ }^{\prime(9)}$.

No decorrer dos relatos das mães adolescentes, há situações que apresentam um cotidiano vulnerável, particularmente relacionado às interações, que mostram lacunas no cuidado. Nesse sentido, estudo aponta, entre os fatores de vulnerabilidades das crianças, aqueles relacionados à dinâmica familiar e ao lugar de moradia $^{(4)}$. Situações de crianças em ambientes desfavoráveis, expostas a diferentes tipos de negligências, com estresse prolongado, ininterrupto ou repetitivo, levam à desregulação no sistema neuroendócrino, que gera danos ao organismo e ao desenvolvimento, denominado de estresse 'tóxico' (19-20).

No que concerne às dificuldades apresentadas na amamentação, a percepção do pouco leite foi um aspecto fortemente relatado por mães adolescentes ${ }^{(21)}$, o que aparece como entrave para o sucesso da duração do aleitamento materno. Nesse âmbito, as atitudes e as formas de interação do profissional de saúde com as mulheres precisam ser repensadas, buscando o conhecimento das singularidades de cada mulher referentes à amamentação, a criação de vínculo desde o pré-natal e o preparo para o aleitamento, bem como a troca de experiências e conhecimentos para decisões compartilhadas ${ }^{(22)}$.

A etapa de introdução da alimentação complementar é crítica, havendo prejuízos para a saúde infantil caso ocorra inclusão antecipada ou inadequada de alimentos ${ }^{(23)}$. Considerando que a família possui papel decisivo na formação de um padrão de comportamento alimentar, cabe destacar também que profissionais de saúde devem orientar tanto os cuidadores no tocante às práticas de alimentação complementar adequadas, quanto as ações governamentais, com o objetivo de defender a saúde infantil e otimizar o crescimento e desenvolvimento das crianças menores de dois anos ${ }^{(23)}$.

Ao deparar-se com os sentimentos de rejeição para com a filha, a mãe adolescente sofre porque não consegue atender ao ideal materno, construído socialmente, em que a maternidade é denotada como sinônimo de amor, carinho e afeto ${ }^{(24)}$. Esses aspectos sugerem que determinado tempo foi necessário para que a adolescente aceitasse a criança, e esta pode passar a assumir papel central na sua vida.

Para lidar com dificuldades, as mães mencionaram a importância de contar com o apoio de outras pessoas no cuidado. No cuidado cotidiano infantil, a família emerge como uma importante fonte de suporte, destacando-se o papel desempenhado pela avó materna da criança, aspecto também encontrado em outros estudos $^{(8,11)}$.

Evidenciou-se que, quando o pai e a família paterna colaboraram de forma incipiente no cuidado infantil, há uma sobrecarga da mãe adolescente e da família materna, que buscam recursos para suprir a carência afetiva e/ou financeira ocasionada pela ausência ou pouca participação paterna no cuidado cotidiano da criança. Destaca-se, portanto, o papel da família, que colabora de diversas formas para a satisfação de necessidades e proteção da criança e apoio à mãe/pai adolescente.

Diante de situações de vulnerabilidade, a enfermagem, ao apropriar-se da concepção do apoio social 
como um fator de proteção da mãe e da criança, contribui para que seja construído um cuidado integral, potencializando, ainda, as condições de vida da adolescente que vivencia a maternidade ${ }^{(11)}$.

Estudo aponta que as orientações fornecidas por profissionais de saúde auxiliam as mães adolescentes no desempenho do cuidado do bebê $\hat{~}^{(17)}$. Assim, a implementação de práticas educativas, com respeito às singularidades de cada mãe e facilidades ao aprendizado, auxiliam na superação de medos e no estabelecimento de maior segurança para o cuidado com o bebê $\hat{~}^{(25)}$. Ainda, é preciso frisar que a educação em saúde, que auxilia a mãe a construir e ampliar suas habilidades maternas, configura-se como fundamental para a socialização do cuidado humano ${ }^{(25)}$.

Para o desenvolvimento de um cuidado protetor da saúde infantil, o enfermeiro, em suas ações de educação em saúde, deve buscar orientar as mães não somente quanto ao modo correto de cuidar, mas também sobre aspectos a serem destacados no cuidado cotidiano ${ }^{(8)}$. No âmbito da saúde, os profissionais precisam ter uma proximidade com as mães e famílias, buscando a realização de ações para reduzir as situações de vulnerabilidades e para apoiá-las na construção de conhecimentos e habilidades para um cuidado protetor.

Assim, os resultados deste estudo sugerem que as potencialidades da mãe adolescente são mais evidentes quando ela é apoiada, permitindo demonstrar capacidade de enfrentamento e superação de vulnerabilidades, e estabelecer vínculos afetivos com a criança.

\section{CONCLUSÃO}

O cuidado materno na adolescência apresentou-se como uma experiência singular, sendo de extrema importância a presença de uma rede de apoio que possibilita maior confiança e prontidão para o cuidado promotor do desenvolvimento infantil.

O presente estudo reafirmou a importância dos relatos maternos sobre o cuidado em saúde das crianças, o que possibilita a identificação de elementos relevantes para o acompanhamento da saúde infantil, a serem mais explorados pelos profissionais de saúde, em especial pela enfermagem. As intervenções diante de fragilidades, o enfrentamento das vulnerabilidades e a oferta de apoio favorecem o incremento da confiança materna.

Cabe ressaltar que o cuidado materno na adolescência é objeto de estudo amplo, sendo relevante expandir para outras pesquisas, tendo em vista a observação do cuidado e das práticas profissionais, em diferentes cenários.

\section{Agradecimentos}

Ao Conselho Nacional de Ciência e Tecnologia e à Fundação de Amparo à Pesquisa do Estado de São Paulo. 


\section{REFERÊNCIAS}

1. Andrade RD, Santos JS, Pina JC, Silva MAI, Mello DF. A puericultura como momento de defesa do direito à saúde da criança. Cienc Cuid Saude. 2013;12(4):719-27.

2. Mello DF, Henrique NCP, Pancieri L, Veríssimo MLOR, Tonete VLP, Malone M. A segurança da criança na perspectiva das necessidades essenciais. Rev Lat Am Enfermagem. 2014;22(4):604-10.

3. Brazelton TB, Greenspan SI. As necessidades essenciais das crianças: o que toda criança precisa para crescer, aprender e se desenvolver. Porto Alegre: Artmed; 2002. 213p.

4. Sierra VM, Mesquita WA. Vulnerabilidades e fatores de risco na vida de crianças e adolescentes. Sao Paulo Perspect. 2006;20(1):148-55.

5. Buendgens BB, Zampieri MFM. A adolescente grávida na percepção de médicos e enfermeiros da atenção básica. Esc Anna Nery. 2012;16(1):64-72.

6. Silva MAI, Mello FCM, Mello DF, Ferriani MGC, Sampaio JMC, Oliveira WA. Vulnerabilidade na saúde do adolescente: questões contemporâneas. Cien Saude Colet. 2014;19(2):619-27.

7. Araujo NB, Mandú ENT. Construção social de sentidos sobre a gravidez-maternidade entre adolescentes. Texto Contexto Enferm. 2015;24(4):1139-47.

8. Merino MFGL, Zani AV, Teston EF, Marques FRB, Marcon SS. As dificuldades da maternidade e o apoio familiar sob o olhar da mãe adolescente. Cienc Cuid Saude. 2013;12(4):670-8.

9. Mesquita ALP, Fontes BFS, Oliveira Filho HB, Lopes LGF, Gonçalves MT, Moreira SRG, et al. Trajetórias de mulheres que vivenciaram a gravidez/maternidade na adolescência. Mental. 2011;9(16):443-89.

10. Halonen M, Apter D. [Multiple challenges of teenage pregnancy and maternity]. Duodecim. 2010;126(8):881-7. Finnish.

11. Braga IF, Oliveira WA, Spanó AMN, Nunes MR, Silva MAI. Percepções de adolescentes sobre o apoio social na maternidade no contexto da atenção primária. Esc Anna Nery 2014;18(3):448-55.

12. Rodrigues FRA, Rodrigues DP, Silva LMS, Jorge MSB, Vasconcelos LDPG. Ser mãe adolescente: representações de puérperas adolescentes a partir da técnica do desenho-estória. Rev Min Enferm. 2010;14(3):308-15.

13. Dahmen B, Firk C, Konrad K, Herpertz-Dahlmann B. [Adolescent parenting developmental risks for the motherchild dyad]. Z Kinder Jugendpsychiatr Psychother. 2013;41(6):407-17. German.

14. Jahromi LB, Guimond AB, Umaña-Taylor AJ, Updegraff KA, Toomey RB. Family context, Mexican-origin adolescent mothers' parenting knowledge, and children's subsequent developmental outcomes. Child Dev. 2014;85(2):593-609.

15. Braun V, Clarke V. Using thematic analysis in psychology. Qual Res Psychol. 2006;3(2):77-101.

16. Fontanella BJB, Luchesi BM, Saidel MGB, Ricas J, Turato ER, Melo DG. Amostragem em pesquisas qualitativas: proposta de procedimentos para constatar saturação teórica. Cad Saude Publica. 2011;27(2):389-94.

17. Di Stefano D, Moccellin AS, Fabbro MRC, Hirakawa HS, Accierini LH, Honorato J, et al. Caracterização das condições sociais e de saúde de mães adolescentes no primeiro ano pós-parto em um município do estado de São Paulo. Rev Baiana Saude Publica. 2011;35(4):795-812.

18. Dezoti AP, Alexandre AMC, Tallmann VAB, Maftum MA, Mazza VA. Rede social de apoio ao desenvolvimento infantil segundo a equipe de saúde da família. Esc Anna Nery. 2013;17(4):721-9.

19. Franklin TB, Saab BJ, Mansuy IM. Neural mechanisms of stress resilience and vulnerability. Neuron. 2012;75(5):747-61.

20. Sheridan MA, How J, Araujo M, Schamberg MA, Nelson CA. What are the links between maternal social status, hippocampal function, and HPA axis function in children? Dev Sci. 2013;16(5):665-75.

21. Clapis CV, Fabbro MRC, Beretta MIR. A prática da amamentação de mães adolescentes nos primeiros seis meses de vida do filho. Cienc Cuid Saude. 2013;12(4):704-10.

22. Souza SNDH, Mello DF, Ayres JRCM. O aleitamento materno na perspectiva da vulnerabilidade programática e do cuidado. Cad Saude Publica. 2013;29(6):1186-94.

23. Dias MCAP, Freire LMS, Franceschini SCC. Recomendações para alimentação complementar de crianças menores de dois anos. Rev Nutr. 2010;23(3):475-86.

24. Resta DG, Marqui ABT, Colomé ICS, Jahn AC, Eisen C, Hesler LZ, et al. Maternidade na adolescência: significados e implicações. Rev Min Enferm. 2010;14(1):68-74.

25. Souza Carvalhêdo D, Monteiro Lotufo F, Rodrigues da Silva Barbosa MA, Munhoz Gaíva MA, Lisboa SR. Vivencias y significados del primer baño dado por la puérpera a su hijo recién nacido. Enferm Glob. 2010;(19):1-15. 